\title{
A pesquisa em Ciência da Informação no Brasil: marcos institucionais, cenários e perspectivas
}

\section{Regina Maria Marteleto}

\author{
Programa de Pós-Graduação em Informação, \\ Comunicação e Saúde/PPGICS. Laboratório de \\ Pesquisa em Comunicação e Saúde - \\ Laces/Icict/Fiocruz. Pesquisadora do CNPq
}

"Só existem 'saberes autônomos' porque esses saberes se interligam por meio de milhares de canais a um extenso conjunto de práticas, das quais recebem sua substância e as quais eles, em troca, alimentam. Nesse sentido, nunca existiu uma 'ciência autônoma'."

(Bruno Latour, 2009)

Observa-se nas duas últimas décadas uma maior concentração dos estudos da ciência da informação em relação aos contextos institucional, histórico e epistemológico de sua conformação como disciplina ou campo científico, o que poderia indicar uma maior reflexividade da área de estudos em relação a si própria. Além disso, a disciplina parece assumir de forma mais sustentada o seu pertencimento ao campo das ciências sociais e das humanidades. Esses aspectos fornecem um plano de apoio para se refletir sobre a constituição da pós-graduação e as perspectivas da pesquisa no Brasil e, em seguida, no campo da ciência da informação. Destacase o papel da ANCIB-Associação Nacional de Pesquisa e Pós-Graduação em Ciência da Informação e de seus grupos temáticos de trabalho nesse contexto. Reflete-se ainda sobre como a pesquisa no campo de estudos da informação deve enfrentar os condicionantes de um novo regime de informação e conhecimento configurado pelo mercado e pelas organizações empresariais, de forma diferente de um regime anterior, orientado pelo Estado, pelo público e pela escola.

Palavras-chave: Ciência da informação; pesquisa; pósgraduação; conhecimento 


\section{Information Science Research in Brazil: institutional milestones, scenarios and perspectives}

In the last two decades, the studies of Information Science in relation with institutional, historical and epistemological circumstances have been the subject of growing attention, which could mean a higher level of reflexivity of this field of knowledge towards itself. Furthermore, the area seems to assume its belonging to the field of Social Sciences and Humanities in a more concrete manner. These aspects provide a background for a reflection over the nature of graduate studies and research perspectives in Brazil and in the field of Information Science. The whole of the ANCIB - the Brazilian National Association of Research and Graduate Studies in Information Science is highlighted in this context. Additionally, considerations are made about how research should fight the conditions imposed by a new information paradigm configured by the market and business organizations, rather than the old paradigm, which was oriented towards the State, the public and the educational sector.

Keywords: Information Science; research; graduate studies; knowledge

\section{Introdução}

Nas mais recentes décadas duas orientações merecem realce no campo das ciências da informação em nível mundial. Primeiro, a busca por melhor equacionar o seu campo de perguntas, posição disciplinar, inter e transdisciplinar, objeto de estudo, teorias e métodos, numa perspectiva social e histórica, e não puramente abstrata ou formal. Nesse sentido, parece que o campo começa a exercer aquilo que Bourdieu (2001) denominara reflexividade, referindo-se à necessidade de submeter a ciência a uma análise histórica e sociológica, que permita àqueles que a fazem compreender os mecanismos sociais que orientam a prática científica e a própria estrutura e dinâmica do seu campo disciplinar.

Trata-se de fazer voltar para si mesmo - o pesquisador - os próprios instrumentos teóricos e metodológicos da pesquisa, de modo a realizar a sua auto-análise como produtor social, bem como obter uma reflexão sobre as condições sócio-históricas da possibilidade de existência de uma disciplina, no caso, a ciência da informação. A idéia de reflexividade extrapola a experiência vivida do sujeito pesquisador para englobar a 
estrutura organizacional e cognitiva do seu campo disciplinar, seus objetos, teorias, discursos, verdades e instituições.

Em segundo lugar e no próprio movimento de reflexividade, percebe-se da mesma forma a presença de estudos que evidenciam um esforço maior de sistematização do campo reflexivo da ciência da informação em direção a uma abordagem crítica, histórica e contextual do seu objeto, assumindo a transversalidade do conceito de informação e sua sintonia com as ciências humanas e sociais, ou seja, com as perguntas e questões do seu contexto social e histórico.

Nos termos da sociologia crítica do campo científico desenvolvida por $P$. Bourdieu, a reflexividade epistêmica permite que um campo do conhecimento consiga refletir suas origens e bases históricas e epistemológicas, e assim ganhar legitimidade. Alguns autores, citados em seguida, ilustram esses esforços de reflexividade dos estudos da informação.

Em 1995, na 23a. Conferência Anual da Associação Canadense de Ciência da Informação, Frohmann (1995) apresentou uma palestra sobre política de informação, onde empregou a idéia de regime de informação para nomear os diferentes atores, instituições, veículos e cenários temporais e espaciais que configuram um determinado ordenamento das ações e políticas de informação. Os regimes de informação representam relações sociais e formas específicas de poder que são exercidas em sua abrangência no tempo e no espaço. Mais tarde, em conferência sobre o caráter social, material e público da informação, proferida na abertura do VII Encontro Anual da ANCIB - Associação Nacional de Pesquisa e PósGraduação em Ciência da Informação, em 2006, Frohmann (2008) tratou da necessidade de conciliar estudos sobre o fenômeno da informação nos tempos atuais com os das práticas sociais e públicas e as realidades políticas, da economia e da cultura. Essa seria uma via para a maior qualificação e contextualização do conceito de informação e de outros a ele afetos, como o de documento, que parece esquecido no ar do tempo, face aos pesados aparatos tecnológicos que coletam, processam e disponibilizam informações.

González de Gómez (2002) empregou o conceito desenvolvido por Frohmann para afirmar que um regime de informação é reconhecido por suas linhas de força dominantes. Ele define quem são os sujeitos, as organizações, as regras e as autoridades informacionais e quais os meios e recursos preferenciais de informação, além de regular os padrões de excelência e os modelos de sua organização, interação e distribuição vigentes em certo tempo, lugar e circunstância, conforme certas possibilidades culturais e certas relações de poder.

Couzinet (2000), em estudo realizado a respeito das mediações híbridas que caracterizam a constituição do campo das ciências da informação na França, adota perspectiva semelhante às de Frohmann e González de Gómez, quando procura investigar os atores, veículos e instituições em cena na história e no modo de funcionamento do campo, ao perceber uma ampla rede sócio-técnica de atores institucionais 
múltiplos presentes na conformação híbrida da disciplina naquele país: pesquisadores e profissionais da informação, veículos, eventos, programas e práticas institucionais.

Em outra perspectiva, Boure (2006) reflete que durante muito tempo a história das ciências da informação e da comunicação na França, isto é, a sua institucionalização progressiva nos planos cognitivo e social em contexto espaço-temporal particular, despertou pouco interesse dos membros da comunidade científica. No entanto, pergunta: numa universidade cada vez mais voltada a ignorar tudo o que não tenha uma utilidade imediata e preocupada com indicadores mensuráveis em termos de preparação para a vida profissional, para que serviria a história e a epistemologia de uma disciplina? E responde: "...é justamente porque ela tem uma fraca rentabilidade imediata para a comunidade científica e suas instituições sociais que essa história merece ser construída...e ensinada. Porque se existe alguma utilidade, essa deverá ser alcançada a longo prazo como um elemento estruturante de uma cultura científica." (Boure, 2006, p. 245-246)

Essa perspectiva, da adoção de uma posição de reflexividade sobre o campo de conhecimento e do emprego da idéia de regime de informação para buscar compreender os meandros históricos e contemporâneos das práticas disciplinares e políticas de informação, será aqui utilizada para refletir sobre a pesquisa em ciência da informação no Brasil.

O realce de fundo desse cenário será realizado levando-se em conta o período de transição das últimas décadas, de um regime de informação fundamentado pela ação do Estado para um outro, orientado para o mercado, o qual parece configurar um deslocamento da questão do conhecimento e da informação das esferas estatal, pública, educacional e científica para o domínio empresarial e econômico, além de ressaltar a centralidade da informação, da comunicação e suas tecnologias no mundo globalizado contemporâneo, onde a temática do conhecimento e sua gestão em múltiplos ambientes organizacionais e sociais adquire especial relevância.

Esse novo cenário de mudança de regime encontra nos atores, discursos e instituições do campo informacional e científico em geral elementos que reforçam, resistem ou questionam a nova ordem mundializada da pesquisa, do conhecimento e da informação.

Para assim desenvolver a temática da pesquisa em ciência da informação, 0 artigo se estrutura nas seguintes linhas de desenvolvimento: a) o desenvolvimento da pesquisa no Brasil e os diferentes modos de produção do conhecimento científico; b) a pesquisa e o sistema nacional de pós-graduação, com destaque para o IV Plano Nacional de Pós-Graduação - PNPG; c) a ANCIB-Associação Nacional de Pesquisa e Pós-Graduação em Ciência da Informação e a institucionalização e sedimentação da pesquisa. No final são projetadas algumas questões referentes aos rumos da pesquisa em ciência da informação no país a partir dos eixos apontados e do plano de fundo adotado. 


\section{0 desenvolvimento da pesquisa no brasil e os modos de produção do conhecimento científico e tecnológico}

O entendimento do que seja a pesquisa científica e tecnológica tem variado ao longo do tempo no país. De acordo com periodização empregada por Schwartzmann (2005), diferentes visões e contextos sociais, políticos e econômicos orientaram ao longo do tempo as políticas e ações no campo científico.

Nos primórdios da organização do campo científico no país, no início do séc. XX, prevaleceu uma visão positivista, de engenheiros e militares, quando havia uma compreensão do conhecimento técnico-científico como superior a outras formas de conhecimento. Os produtos da ciência deveriam ser utilizados para tornar o país mais moderno, racional e eficiente, e as universidades enquanto tal ainda não existiam no país.

O conceito da ciência pura demarca a criação da Academia Brasileira de Ciências, em 1916, e, nos anos 30, a criação da USP, com o surgimento de um novo tipo de intelectuais e cientistas para os quais a ciência não era simplesmente um instrumento de ação da sociedade, mas um conhecimento que tem a ver com a cultura, a formação humanística e ampla dos sujeitos e das instituições.

A partir dos anos de 1950, com a criação do CNPq (Conselho Nacional de Pesquisas) e do CBPF (Centro Brasileiro de Pesquisas Físicas), sob a liderança do Almirante Álvaro Alberto, primeiro presidente do $\mathrm{CNPq}$, se fortalece a idéia de que o Brasil deveria dominar a energia atômica e se tornar uma grande potência autônoma. Data também desse período a criação do IBBD (Instituto Brasileiro de Bibliografia e Documentação), com ação da Unesco e de lideranças profissionais e políticas brasileiras (Oddone, 2006). Essa ações marcariam uma presença forte do Estado tanto nas políticas para a ciência e tecnologia, quanto nos programas de informação científica e tecnológica.

A visão da ciência como poder do Estado, que retoma o otimismo tecnológico dos positivistas associado à idéia de poder, situa-se no embrião da criação do CNPq e ressurge com toda força no período militar, a partir dos anos de 1960, a qual corresponde à época do "milagre econômico" quando o governo federal aumenta a sua capacidade de arrecadação de impostos e os recursos públicos abundam. Expandem-se os recursos para a pesquisa, mas agora concentrados em grandes projetos, vários deles de cunho militar. Nos anos de 1970, muda-se o nome e a filiação do $\mathrm{CNPq}$, ligado à presidência da república, para Conselho Nacional de Desenvolvimento Científico e Tecnológico, vinculado ao Ministério do Planejamento Econômico, junto com a recém criada FINEP (Financiadora de Estudos e Projetos). São também desse período os PNDCTs - Planos Nacionais de Desenvolvimento Científico e Tecnológico.

Acompanhando as transformações do perfil do CNPq e da pesquisa brasileira e o movimento disciplinar da informação científica e tecnológica em âmbito mundial, o IBBD (Instituto Brasileiro de Bibliografia e 
Documentação) tem o seu nome alterado para IBICT (Instituto Brasileiro de Informação em Ciência e Tecnologia), em 1976.

Também é nesse período que se cria a pós-graduação nas universidades brasileiras, nos moldes norte-americanos, com a reforma do ensino superior de 1968. Caberia à CAPES - Coordenação de Aperfeiçoamento de Pessoal de Nível Superior, que havia sido criada em 1951, com o objetivo de assegurar a existência de pessoal especializado em quantidade e qualidade suficientes para atender às necessidades dos empreendimentos públicos e privados para o desenvolvimento do país, incentivar, acompanhar e avaliar a expansão da pós-graduação no país. 0 sistema de ensino e pesquisa no Brasil passa a integrar duas políticas diferentes: uma orientada para a formação de recursos humanos para a educação superior (MEC); outra orientada para os grandes projetos tecnológicos, de interesse dos militares. (Schwartzmann, 2005)

A partir dos anos de 1980 esse modelo ambicioso entra em crise, com o agravamento da situação econômica do país e o fim dos governos militares, quando se cria o Ministério da Ciência e Tecnologia, sob a pressão dos cientistas. Nos anos de 1990 começa a tomar peso uma outra maneira de pensar a ciência, estimulando-a a se vincular mais fortemente com o setor produtivo, quando a pesquisa científica passa a ser considerada como parte de um sistema de inovação amplo, incluindo o setor produtivo e empresarial.

O convívio entre diferentes visões do que é ou como deve ser a pesquisa por diferentes atores institucionais: cientistas, órgãos de avaliação e fomento, disciplinas das ciências exatas, biológicas e ciências humanas e sociais, discursos e políticas do Estado, ações e pressões do setor produtivo, configuram um campo de tensões, conflitos e alianças em torno das questões e objetivos das pesquisas, tanto quanto da correlação de forças e parcerias em projetos e programas de pesquisa e de ensino.

Entre os anos de 1990 e 1993 desenvolveu-se um projeto, pelo Conselho de Pesquisa da Suécia, que contou com a colaboração da Universidade da Califórnia, sobre as mudanças na pesquisa científica, tecnológica e de humanidades face às transformações pelas quais vem passando a sociedade no Ocidente, posteriormente publicado em livro. (Gibbons et al., 1994)

As conclusões gerais do estudo, que apontavam alterações na pesquisa científica, baseada no que os autores denominaram de "novo modo de produção do conhecimento científico - o modo II", em contraposição ao modo I, anterior e orientado pelo Estado, apresentam-se da seguinte forma:

1. as pesquisas passarão a depender cada vez mais das exigências do mercado e vão definir-se no contexto da aplicação, pois o conhecimento se difundiu pela sociedade, diversificando-se extremamente as demandas e expectativas;

2. as pesquisas terão características transdisciplinares (e não interdisciplinares). Voltadas para a sociedade, tanto 
em termos de aplicação quanto como de definição, são sobretudo dinâmicas, podendo englobar sucessivamente novos atores tanto do campo científico quanto externo;

3. ocorrerá uma ampliação do número potencial de locais onde o conhecimento é gerado, além de universidades e centros de pesquisas;

4. as pesquisas estarão sujeitas ao controle social, com o surgimento de novos grupos desejosos de fazer-se representar nos órgãos de decisórios da "política científica e tecnológica", pois cresce a ingerência que a técnica e a ciência têm na vida de cada um. Alguns exemplos: as questões do meio ambiente; a biotecnologia;os que desejam influir nos meios de comunicação de massa; o aborto e o planejamento familiar.

A partir dessas demarcações e resultados, que sintetizam a direção e a visão da pesquisa em nível internacional, pergunta-se: a qual sociedade o estudo se refere? Quais seriam suas instituições de representação e participação social nos destinos da pesquisa e do conhecimento científico? Existem espaços na sociedade brasileira para tais debates e deliberações? Quem seriam esses novos atores? Como criar tais espaços? Que papel caberia à pesquisa em ciência da informação face a esse novo contexto?

Para assim refletir, é oportuno e relevante considerar, ainda que sinteticamente, o quadro de conformação da pós-graduação brasileira.

\section{0 sistema nacional de pós-graduação e a pesquisa}

Por circunstâncias históricas e institucionais de país de desenvolvimento sócio-econômico tardio, nas universidades brasileiras, que se organizam no país a partir dos anos 30, desenvolveu-se primeiramente um sistema de ensino superior, baseado na formação e no ensino e, posteriormente, um sistema de pós-graduação, onde se localizam prioritariamente as atividades de pesquisa no país (cerca de $90 \%$ das pesquisas).

A expansão do sistema nacional de pós-graduação deu-se a partir da década de 1970, com a reforma do ensino superior, a qualificação dos quadros docentes e o desenvolvimento mais sustentando das atividades de pesquisa, no contexto de políticas educacionais e de ciência e tecnologia organizadas pelo Estado militar-autoritário brasileiro, no quadro dos planos e metas para o desenvolvimento econômico e a construção da soberania nacional.

No ano de 2004 foi elaborado, por uma Comissão de especialistas nomeados pelos ministérios da Educação e da Ciência e Tecnologia, o IV Plano Nacional de Pós-Graduação, que contém diretrizes e metas para a pesquisa e a Pós-Graduação para o período de 2005 a 2010. PNPGs 
(Planos Nacionais de Pós-Graduação) são documentos formulados periodicamente pelos organismos e agências nacionais encarregados da política nacional de pós-graduação e de ciência e tecnologia, com o objetivo de rever o que já foi realizado, definir metas a serem alcançadas, formular prioridades, estabelecer as coordenadas que presidirão as políticas nacionais na área $\mathrm{e}$, quando necessário, realizar eventuais ajustes no sistema. (BRASIL, 2005)

Entre as vantagens do processo de elaboração dos planos nacionais de pós-graduação está a mobilização das agências de fomento, dos programas de pós-graduação do país, do Fórum de Pró-Reitores de Pesquisa e Pós-Graduação, dos professores-pesquisadores, das sociedades científicas e dos pós-graduandos em torno de um debate cujo objetivo último é aperfeiçoar o sistema para melhor responder às necessidades do presente e aos desafios do futuro do Brasil e de todos os brasileiros. A existência de um PNPG faz com que o desenvolvimento científico, tecnológico e educacional do país não fique à mercê de interesses de ocasião. (CURY, 2004) No decorrer da expansão e consolidação da pósgraduação no país foram elaborados quatro PNPGs, dos quais se resumem a seguir os pontos principais.

- I PNPG (1975-1979): a pós-graduação é considerada como subsistema do sistema universitário e este, por sua vez, do sistema educacional. É enfatizado o objetivo de expansão do sistema como um objeto do planejamento estatal;

. II PNPG (1982-1985): o objetivo central continua a ser a formação de recursos humanos qualificados para as atividades docentes, de pesquisa e técnicas visando o atendimento dos setores público e privado. A ênfase agora recai sobre a qualidade do ensino superior e, mais especificamente, da pós-graduação, sendo necessários para isso a institucionalização e o aperfeiçoamento da avaliação que já existia embrionariamente desde 1976, com a participação da comunidade científica;

- III PNPG (1986-1989): reafirma a necessidade de formação de recursos humanos de alto nível, pois não existia um quantitativo suficiente para se atingir a plena capacitação científica e tecnológica . A ênfase do plano é aumentar a capacidade da atividade de pesquisa nas universidades e a integração da pós-graduação ao sistema de C\&T, assim como a aproximação da pós-graduação com o setor produtivo.

Em seguida, mais de dez anos se passaram, sem a elaboração de planos nacionais de pós-graduação, até que se apresentou o IV PNPG (2005-2010). Os pontos principais ressaltados nesse documento referemse à rápida expansão da pós-graduação e da pesquisa nas últimas décadas, muito embora permaneçam as assimetrias regionais. A necessidade de expansão de linhas de financiamento à pesquisa, por meio de fontes estatais e privadas (os chamados fundos setoriais); a criação de novos modelos e parcerias de pós-graduação; 0 incremento da cooperação internacional, com o aumento do fluxo inter países de pesquisadores e estudantes. Se nas primeiras décadas os esforços despendidos voltavam-se para a formação de novos quadros de 
pesquisadores e para a expansão da pós-graduação, nesse último plano insiste-se na melhor qualificação dos Programas e na sua expansão com excelência.

A ANCIB - Associação Nacional de Pesquisa e Pós-Graduação em Ciência da Informação, chamada, como as demais sociedades científicas, a apresentar sugestões para a comissão de elaboração do IV PNPG, reuniu as seguintes reflexões sobre os pontos considerados pela comissão, orientada pela situação da ciência da informação (ANCIB, 2004):

a) modelos de organização da pós-graduação; flexibilidade; interdisciplinaridade; debilidades, potencialidades e oportunidades do sistema nacional de pós-graduação: o sistema de pós-graduação tem um grande desafio a enfrentar, que é o de fazer combinar os diferentes modos de produção de conhecimento e a interdisciplinaridade. Ou seja, reconhecer, por um lado, que as ciências exatas, da saúde e humanas apresentam diferentes dinâmicas e modos de produção do conhecimento e, por outro lado, lidar com a interdisciplinaridade de forma a não negar a disciplinaridade.

Cumpre dessa forma discutir os modos diferentes de produção do conhecimento pelas diferentes grandes áreas, de modo a atingir padrões de flexibilidade que incorporem as diferenças mas preservem a noção de um "sistema". Historicamente a CAPES, em seus padrões de avaliação, partiu de um modelo único. A partir da avaliação do triênio 1998/2000 as áreas introduziram algumas especificidades mas os conceitos fundamentais que sustentam a avaliação ainda seriam originários das ciências exatas e da saúde. Sugere-se, portanto, que a revisão de critérios seja retomada e aprofundada, tendo-se claro até qual ponto é possível introduzir uma flexibilidade que não comprometa a noção de "sistema". Propõe-se, portanto, que se estabeleçam regras de equivalência (ou compatibilidade) entre critérios básicos das diferentes áreas que permitam "traduzir" critérios de áreas para um "meta critério CAPES", não adotado por nenhuma área mas implementado, de formas diferenciadas, pelas diferentes áreas. De toda forma, e acima de tudo, a "qualidade" deve ser o critério primeiro. Trata-se de "traduzir" o conceito de qualidade para as especificidades das áreas. Ainda neste item, faz-se necessário apontar para a oportunidade de se considerarem diferentes formatos para os programas de pós-graduação e suas linhas de pesquisa, que contemplem as necessidades e especificidades regionais e promovam uma maior proximidade com os problemas da sociedade brasileira;

b) financiamento do sistema nacional de pós-graduação: a produção de conhecimento para a melhoria geral das condições de vida no país é obrigação do Estado, embora o setor privado possa contribuir neste financiamento. O sistema nacional de pós-graduação vem contribuindo de forma decisiva na produção deste conhecimento, razão pela qual ele deve receber todo o apoio financeiro do Estado. No entanto, face à demanda crescente por apoios financeiros, o Estado não vem conseguindo alocar verbas suficientes para a pesquisa. Prever um percentual de recursos estabelecido a partir de uma referência (por exemplo, investimento global 
anual em educação pelo país) e partindo de um patamar (por exemplo, o maior investimento anual dos últimos dez anos), garantindo que, em qualquer circunstância, nos próximos anos, o investimento não seja inferior ao período anterior. É necessário prever como fontes: o Tesouro Nacional, via orçamento do MEC e do MCT; recursos dos Fundos Setoriais e recursos oriundos de uma taxação específica para investimento em formação de mestres e doutores incidente sobre as instituições privadas de ensino superior,com base no faturamento do último ano;

c) identificação de áreas pritoritárias: há que se atentar para a importância das áreas profissionais clássicas do conhecimento na dinâmica cultural moderna, como a biblioteconomia, a arquivologia e a museologia, assim como de outros sub-campos que se organizam em função das novas modalidades de leitura, representação, expressão e acesso à informação as modernas mídias eletrônicas. Outras áreas prioritárias seriam aquelas que se dedicam à preservação, organização e acesso às mídias digitais. A identificação dessas e outras áreas prioritárias seria realizada a partir do fortalecimento e expansão de linhas de pesquisa dos programas, contratação de pesquisadores, investimento de recursos financeiros para os projetos de pesquisa. Muitos dos temas e áreas emergentes devem ser desenvolvidos pela formação de grupos inter-programas e interinstitucionais;

d) processo de avaliação e acompanhamento: a história deste processo é exemplar e vitoriosa, reconhecida por todos, e permitiu a organização de um sistema de pós-graduação forte e de qualidade em curto espaço de tempo. No entanto, o processo de avaliação e acompanhamento está se tornando um processo "pesado". O desafio, neste sentido, reside na elaboração de indicadores - diferenciados de acordo com as áreas- indicadores estes que permitiriam produzir uma avaliação consistente e de qualidade mas com um menor dispêndio de energia. Neste aspecto merece especial atenção a Qualis de periódicos. Indicadores para os livros, eventos, publicações eletrônicas, dentre outros, necessitam ser estabelecidos com a participação ativa da comunidade científica e o reconhecimento das especificidades dos diferentes campos de conhecimento;

e) setor produtivo e política industrial: em Ciência da Informação ainda não se defronta muito com as questões de relacionamentos entre a pós-graduação e os setores produtivos e a política industrial, talvez pelo caráter historicamente público e estatal das questões relativas à informação especializada e social. No entanto, o diálogo entre a pesquisa e o setor produtivo começa a permear o campo no momento em que há uma nova reconfiguração das questões do conhecimento e da informação e suas técnicas e metodologias de gestão. A CAPES deve zelar pela qualidade da pesquisa na pós-graduação, gerando padrões de distribuição de responsabilidades e autorias quando este diálogo é exercido, estimulando ainda, junto com as agências de fomento, o apoio financeiro do setor privado para as pesquisas realizadas nas universidades. Há que se pensar, a partir de ampla discussão e estudo, a participação das universidades particulares na oferta de cursos de pós-graduação; 
f) atuação das agências de fomento: tendo em vista que o fomento é insuficiente, torna-se mais do que nunca imprescindível que haja uma total transparência nos critérios que determinam a designação de assessores, consultores e representantes e a alocação de verbas e a priorização de pedidos. Num quadro onde, de um lado, existe um sistema de acompanhamento, avaliação e fomento já estabelecido, e de outro, a necessidade de apoio, expansão e fortalecimento dos programas de pósgraduação e suas linhas de pesquisas, atenta-se para a necessidade de revisão de critérios de avaliação e fomento, de modo que se resguarde o que já está constituído e rendendo bons resultados, mas que se reforce o investimento em áreas e regiões deficitárias e/ou emergentes. Empregando uma imagem, as agências têm aprendido a praticar a eutanásia de programas e linhas de pesquisa, mas ainda não aplica práticas preventivas e de reversão de situações de adoecimento. Este é um importante desafio para as agências de fomento;

g) cooperação internacional: a cooperação internacional é obviamente desejável, mas deve-se fazer um esforço para mudar a "leitura" da expressão "cooperação internacional", ainda por demais interpretada como uma operação em mão única, paternalista, pela qual renomados cientistas estrangeiros são convidados a trazer sua colaboração. A "cooperação" deve passar a ser vivenciada e entendida como um processo em mão dupla e reconhecidas e estimuladas as parcerias de pesquisa e formação estabelecidas pelos Programas e seus congêneres no exterior;

h) regionalização (estratégias para enfrentar assimetrias regionais):a regionalização, obviamente desejável, deve ser incentivada, preservada a qualidade. De todo modo, a regionalização com qualidade pressupõe a fixação de docentes experientes em regiões com menor concentração de pesquisadores titulados. Devem ser estimulados os concursos públicos em número adequado para provimento de vagas nas universidades em áreas geográficas deficitárias para a criação de grupos de pesquisa e aceleração com qualidade da formação para a pesquisa e a expansão da pós-graduação.

Por ocasião da última avaliação trimestral dos programas de pósgraduação realizada pela CAPES, em 2007, ressaltaram-se alguns pontos gerais relativos aos programas e suas pesquisas. Primeiro, o necessário teor comparativo da avaliação, respeitando-se as peculiaridades das áreas e o impacto social que cada uma considera dever ter. A importância da produção científica bem qualificada dos professores-orientadores, tanto quanto a dedicação e capacidade para a formação de mestres e doutores de alto nível. A valorização das diversas formas de divulgação do conhecimento e seus diferentes veículos de publicação: o livro, o periódico, os meios de divulgação artística, as patentes, etc. Resumindo as duas missões principais da avaliação, Ribeiro (2007) aponta o foco no aluno e na sua formação com excelência e o estímulo ao avanço na produção do conhecimento. 


\section{A pesquisa em ciência da informação - contextos, marcos históricos e institucionais}

Apresentado esse rápido panorama inicial sobre a pós-graduação e a pesquisa no Brasil, passa-se agora a apontar alguns marcos da institucionalização da pesquisa em Ciência da Informação, a qual se estruturou num regime de informação ancorado no comando do Estado e num quadro de políticas desenvolvimentistas do pós-guerras, conduzidas junto aos países subdesenvolvidos com orientação da UNESCO.

As atividades de informação no Brasil sempre tiveram uma forte presença do Estado. Em seus órgãos de gestão, educação e cultura promoveu-se o desenvolvimento e a institucionalização da Biblioteconomia, depois da Documentação e, por fim, da Ciência da Informação a partir dos anos de 1950, com a criação do Instituto Brasileiro de Bibliografia e Documentação -IBBD, que no final dos anos de 1970 passou a denominar-se IBICT-Instituto Brasileiro de Informação em Ciência e Tecnologia, assinalando a preocupação do Estado e da comunidade científica com as políticas de informação para as atividades de ciência e tecnologia no país.

As políticas e ações de informação nesse período estavam sintonizadas com as idéias da FID, por intermédio da UNESCO e da IFLA, as quais levaram à fusão contextual da Biblioteconomia com a Documentação. Em 1970 o então IBBD cria o primeiro Mestrado em Ciência da Informação no país, cujos primeiros professores-pesquisadores eram norte-americanos ou ingleses. Esse Mestrado, por sua vez, foi o responsável pela formação dos professores-pesquisadores de outros cursos de pós-graduação criados a partir dos anos de 1970 nas universidades brasileiras. Em 1972 o IBBD lança a revista Ciência da Informação, sem interrupção de publicação até os dias de hoje e um dos principais veículos de divulgação de pesquisas e práticas de informação, atestando a hibridação acadêmico-profissional das atividades de informação no país.

Entretanto, o cenário internacional da ciência e tecnologia transformou-se dramaticamente a partir dos anos 80 e uma nova realidade se desenhou para as políticas e atividades científicas e tecnológicas no país, diferente daquela vivenciada entre os anos de 1950 e 1970, onde havia uma forte presença do Estado no setor. A partir dos anos 80, o novo modo de produção científica é mais pragmático, interdisciplinar e relacionado aos interesses comerciais e empresariais do que fora antes. Suas principais características, segundo Schwartzman et al (1995) são:

1. a aproximação entre ciência, tecnologia, indústria e mercado, decorrente das necessidades não só de inovação de produtos e processos pelas empresas, mas também de novas qualificações para acompanhar as novas concepções e práticas de gestão. Há ainda uma 
preocupação renovada com questões de propriedade intelectual, que acompanham a grande expansão de uma verdadeira indústria do conhecimento, do comércio, de marcas e patentes, de assistência técnica e das consultorias internacionais;

2. o ritmo acelerado da inovação tecnológica e da competição no mercado, o que exige das empresas capacidade permanente de mudar a sua organização interna, absorver novas tecnologias e processos e gerar novos produtos e tecnologias de gestão;

3. quanto à ciência, é uma atividade que se torna cada vez mais global. Com a velocidade e os baixos custos dos fluxos internacionais de informação, pesquisadores e centros de pesquisa estão em constante interação e contato direto, gerando um ambiente de comunicação e padrões de produção científica a serem assimilados por pesquisadores e centros de pesquisa no mundo todo, independente dos ambientes culturais e sociais de cada país.

Configura-se um novo contexto social, político e econômico mundializado para a ciência e a tecnologia. De atividade afeita às políticas e iniciativas do Estado, e apesar da presença estatal na formulação de metas de avaliação e financiamento, agora novos atores se fazem presentes: o mercado e o setor empresarial, o que ocasiona algumas situações especiais para o campo de estudos da informação. Primeiro, um certo deslocamento da "questão do conhecimento e da informação" da esfera estatal para a esfera produtiva-organizacional-empresarial. Segundo, uma nova reacomodação da ciência da informação como campo disciplinar, seja por conta do entendimento do que seja ciência, quanto do papel da informação como vetor do funcionamento do mercado, dos seus fluxos e dos novos ambientes empresariais e organizacionais.

Esse novo enquadramento da questão do conhecimento e da informação parece apontar para a constituição de um novo regime de informação, que inaugura novas questões e desafios para a pesquisa em ciência da informação de uma forma geral ,com incidências especiais em diferentes contextos culturais, políticos e econômicos.

\section{O lugar da pesquisa em ciência da informação}

Para desenhar o cenário da pesquisa em Ciência da Informação que se faz atualmente no Brasil, é necessário fazer, ainda que rapidamente, a distinção entre dois tipos de pesquisa:

1. aquela realizada nas universidades $e$ institutos de pesquisa, onde estão os programas formais de ensino, 
formação e pesquisa. É aí que funcionam os programas de pós-graduação;

2. a pesquisa realizada na prática por profissionais egressos da pós-graduação e atuando na gestão e nas práticas de informação em serviços e sistemas de informação especializados. No Brasil tais pesquisadores atuam principalmente em órgãos estatais das áreas de saúde, educação, agricultura, produção de petróleo e energia nuclear, dentre outros.

Apesar da importância dos dois tipos de pesquisa para a expansão e a qualificação do campo disciplinar da ciência da informação, existe um distanciamento entre os dois grupos de pesquisadores o que se explica, em parte, pela separação entre pesquisa e aplicação do conhecimento que se estabeleceu na ciência de um modo geral e, de modo peculiar, no Brasil. No entanto, é importante lembrar que o distanciamento entre pesquisadores acadêmicos e pesquisadores profissionais, assim como o modo de entendimento diferenciado sobre a pesquisa no campo de estudos das ciências da informação, está associado também ao perfil acentuadamente profissional e professoral da área no Brasil, fundada sob o pioneirismo de profissionais da Biblioteconomia e da Documentação atuantes em grandes órgãos públicos e próximos das esferas de poder do Estado.

Para os propósitos desse trabalho, como se vê, e mesmo reconhecendo a importância da pesquisa aplicada realizada por profissionais, a ênfase recai sobre a pesquisa produzida no âmbito dos programas de pós-graduação em ciência da informação, pois são esses efetivamente que fazem parte do sistema acadêmico de produção do conhecimento no país.

Atualmente existem no Brasil 10 programas de pós-graduação em ciência da informação, sendo que 5 possuem o mestrado e o doutorado e outros 5 apenas o mestrado. Existe ainda um mestrado profissional, de acordo com a Relação de Cursos Recomendados e Reconhecidos, disponível no sítio da CAPES (2009). Além desses, outros quatro programas de áreas correlatas incluem linhas e temáticas de pesquisa em informação e boa parte dos seus pesquisadores têm formação em ciência da informação. As áreas de concentração e respectivas linhas de pesquisa dos programas agrupam-se em geral nos seguintes eixos temáticos: a) teoria e epistemologia da informação; b) gestão da informação e do conhecimento; c) mediação, disseminação e uso da informação; d) organização e tratamento da informação.

$\mathrm{Na}$ classificação de áreas do conhecimento empregada pelas agências de avaliação e fomento à pesquisa - CAPES/MEC e CNPq/MCT a Ciência da Informação faz parte da grande área "Ciências Sociais Aplicadas" junto com as áreas de Comunicação e de Artes. 
Desde os anos de 1970 e apesar da expansão acelerada do sistema de pós-graduação no Brasil, a pós-graduação em ciência da informação teve um desenvolvimento pouco expressivo, se comparada com outras áreas correlatas e afins, como a comunicação, por exemplo. As duas áreas iniciariam seus cursos de pós-graduação a partir dos anos de 1970 e tiveram boa e semelhante expansão nos anos de 1980 . No entanto, a partir dos anos de 1990 o ritmo de crescimento das duas áreas começa a se diferenciar. Por exemplo, entre 1996 e 2003, o número de programas em comunicação cresceu $200 \%$, enquanto os de ciência da informação apenas 50\%. Em 2009, a ciência da informação conta com 10 programas, enquanto a comunicação chega aos 37 programas, segundo a Relação de Cursos Recomendados e Reconhecidos, disponível no sítio da CAPES (2009).

Algumas pistas poderiam ser apontadas para essa acentuada diferença no crescimento dos Programas das duas áreas desde os anos de 1990. Ambas as disciplinas têm perfil interdisciplinar, no entanto a comunicação ampliou mais o ângulo de estudo do seu objeto ao aceitar em seu campo pesquisadores de áreas de formação diferenciadas, além de demarcar com maior clareza e investimento teórico o seu caráter de disciplina das ciências sociais. Se isso às vezes trouxe prejuízo nas avaliações da pós-graduação, acentuando o foco multicentrado da área de comunicação, por outro permitiu maior sedimentação e aprofundamento das suas questões, conceitos e objetos de estudo. Por outro lado, a expansão da pós-graduação nessa área foi acompanhada pelo crescimento quantitativo e qualitativo dos cursos de graduação em comunicação, o que permitiu um contingente de candidatos bem preparados para o ingresso na pós-graduação e, posteriormente, para atuar como pesquisadores, em processo cíclico e em cadeia.

$\mathrm{Na}$ ciência da informação, a interdisciplinaridade vem sendo mais anunciada discursivamente do que colocada em prática em atividades de pesquisa. Uma das razões para tanto parece ser 0 caráter acentuadamente profissional e aplicado dos estudos da informação, o que situa suas questões e problemas mais no nível prático-operacional dos serviços e sistemas de informação, do que no plano epistemológico, histórico e social da geração, circulação e apropriação da informação. Além disso, os cursos de graduação mais próximos do campo da ciência da informação - biblioteconomia, arquivologia e museologia - não cresceram nos últimos anos nem quantitativamente e nem qualitativamente, a ponto de proporcionar candidatos em número expressivo à pós-graduação.

Embora a ciência da informação, como área interdisciplinar de pósgraduação e pesquisa, acolha e continuará acolhendo candidatos oriundos de diversas formações, como a comunicação, administração, informática e ciências sociais, dentre outras, é desejada, pela própria organização do sistema de ensino superior no Brasil, que estimula a integração entre os diferentes níveis de ensino, que exista um elo prioritário entre um programa de pós-graduação e área(s) correlatas de graduação, a fim de 
permitir o crescimento articulado e sustentado do ensino, da formação e da pesquisa científica.

Nas mais recentes avaliações trienais da CAPES e nas questões debatidas pela comunidade de pesquisadores, juntamente com representantes das agências e especialistas na temática da pesquisa e da pós-graduação em ciência da informação, observam-se as seguintes questões e perspectivas para a pesquisa e a pós-graduação na área: a área tem crescido, tanto do ponto de vista quantitativo quanto qualitativo, ressaltando-se a inserção mais acentuada das pesquisas no campo da ciência da informação e a produção bibliográfica resultante desse esforço. No entanto, persistem alguns aspectos que merecem atenção, dos quais o mais grave é a observação de que são ainda raros os grupos ou laboratórios de pesquisa bem constituídos, que agrupem pesquisadores seniores com forte presença e liderança em projetos de pesquisa, recémdoutores, alunos-bolsistas de graduação e pós-graduação, profissionais, técnicos e outros.

Em 2004, por ocasião de um workshop organizado pela ANCIB para o debate e reflexão sobre os rumos da pesquisa e da pós-graduação na área de ciência da informação, constatou-se que os programas deveriam continuar atentos à construção e manutenção da sua consistência interna e, ao mesmo tempo, procurar desenvolver esforços para aumentar seu corpo docente e publicações. Apontou-se também para a necessária articulação dos programas de pós-graduação com os cursos de graduação para a esperada integração e fortalecimento mútuo desses níveis de ensino. Lembrou-se ainda que, dado que existe uma competição por espaço político, recursos e visibilidade entre as diversas áreas da pósgraduação, é necessário que os programas de pós-graduação em ciência da informação assumam um comportamento mais arrojado e inovador, ensejando esforços para manter o que já conseguiram e para ganhar outros espaços, por meio, dentre outros, do estabelecimento de alianças com áreas afins, de modo a conjugar esforços, num momento em que o sistema de pós-graduação ultrapassou os seus tempos heróicos de expansão, na década de 1990, para buscar hoje a excelência, em ambiente competitivo das áreas e dos programas entre si, promovendo novas políticas de controle e qualidade. (GOMES, 2004)

\section{A ANCIB (Associação Nacional De Pesquisa E Pós- Graduação Em Ciência Da Informação) e a pesquisa}

A ANCIB é uma sociedade científica, criada em 1989, que representa a comunidade de pesquisadores da área, com o objetivo político e acadêmico de mediar seus interesses junto às agências estatais de fomento e avaliação, assim como estimular o compartilhamento de idéias e experiências entre os pesquisadores e abrir canais de interlocução acadêmicos em níveis nacional e internacional. 
A associação tem sido, também, o espaço onde pesquisadores e estudantes discutem acerca da pesquisa em Ciência da Informação em vista das atuais mudanças que apontam para um período de transição entre diferentes regimes de informação. Abrem-se espaços para aqueles que aceitam, questionam ou resistem às mudanças em curso. Para tal fim, atua em duas frentes principais, o Fórum de Coordenadores dos Programas de Pós-Graduação, que acompanha e debate as questões relativas ao funcionamento dos cursos, sua expansão e qualificação científico-acadêmica, e os Encontros Nacionais de Pesquisa em Ciência da Informação (Enancib), que reúnem os pesquisadores em Grupos Temáticos de Trabalho (GTs), para o debate e o aprofundamento das questões de pesquisa.

Uma das metas da associação é agregar como associados institucionais ou individuais, tanto os programas de pós-graduação em ciência da informação e seus pesquisadores e estudantes, quanto os programas ligados a áreas afins ou interdisciplinares, de maneira a obter maior articulação e fortalecimento mútuo das atividades de pesquisa e de formação de pesquisadores. A ANCIB reúne atualmente 13 Programas associados, de acordo com dados fornecidos em seu portal. A partir de 2004 conta com uma lista eletrônica de discussão entre os associados que atualmente reúne cerca de 520 inscritos. Também são realizados encontros e discussões específicos onde se debatem questões relacionadas aos aspectos políticos, acadêmicos e gerenciais da pesquisa e dos Programas, como os encontros regionais e o Workshop sobre a Pesquisa e o Ensino na Pós-Graduação em Ciência da Informação, realizado em 2004.

A ANCIB congrega atualmente nove grupos de trabalho, cujas temáticas indicam as tendências da pesquisa no campo da ciência da informação e áreas afins, atestando ainda o esforço da associação em reunir as áreas relacionadas aos estudos da informação, com intenção de promover a vitalidade do campo:

GT1 - Estudos Históricos e Epistemológicos da Ciência da Informação

GT2 - Organização e Representação do Conhecimento

GT3 - Mediação, Circulação e Uso da Informação

GT4 - Gestão da Informação e do Conhecimento nas Organizações

GT5 - Política e Economia da Informação

GT6 - Informação, Educação e Trabalho

GT7 - Produção e Comunicação da Informação em CT \& I

GT8 - Informação e Tecnologia

GT9 - Museu, Patrimônio e Informação

Em 2005, atendendo convite da Comissão Especial de Estudos CNPq, CAPES e FINEP, a ANCIB, juntamente com a representação da área de Ciência da Informação na CAPES, elaborou um conjunto de comentários e sugestões para a alteração da Tabela de Áreas do Conhecimento - TAC, de modo a obter uma representação mais condizente com o avanço e a configuração da pesquisa no campo de 
estudos da informação. Gerou-se um documento apresentado à Comissão, depois de amplo debate com a comunidade dos Programas filiados à ANCIB, no qual se apresentavam oito sub-áreas dentro da área Ciência da Informação, abarcando as temáticas e linhas de pesquisa em desenvolvimento nos programas de pós-graduação e nos grupos de trabalho da ANCIB, além de caracterizarem o campo em âmbito internacional:

FUNDAMENTOS DAS CIÊNCIAS DA INFORMAÇÃO

Teoria e Campo Epistemológico

Métodos de Pesquisa nas Ciências da Informação

ORGANIZAÇÃO E RECUPERAÇÃO DA INFORMAÇÃO

Organização da Informação

Recuperação da Informação

MEDIAÇÃO, DISSEMINAÇÃO E USO DA INFORMAÇÃO

Memória Social e Informação

Recepção e Uso da Informação

Comunidades e Usos da Informação

Informação e Processos Simbólicos e Culturais

GESTÃO DE SISTEMAS, UNIDADES E RECURSOS DE INFORMAÇÃO

Gestão de Sistemas e Unidades de informação

Gestão de Recursos Informacionais

Preservação, Conservação e Restauro de Acervos

POLÍTICA, ÉTICA E ECONOMIA DA INFORMAÇÃO

Políticas Públicas de Informação

Ética e Informação

Economia Política da Informação

PRODUÇÃO DA INFORMAÇÃO E COMUNICAÇÃO CIENTÍFICA

Informação para Diagnóstico, Mapeamento e Avaliação de C\&T

Bibliometria, Cientometria e Infometria

TECNOLOGIAS DA INFORMAÇÃO E COMUNICAÇÃO

Arquitetura da Informação

Bancos e Bases de Dados Informacionais

Redes Eletrônicas de Informação

CAMPO DE TRABALHO INFORMACIONAL

Profissionais da Informação e Mercado de Trabalho

Formação Profissional

É nesse escopo, argumentava-se, que se incluem os trabalhos de pesquisa e suas aplicações em bibliotecas, arquivos, museus, sistemas de informação, bases de dados, bibliotecas digitais e outros dispositivos e ambientes da informação especializada e social. Os alunos oriundos dos cursos de graduação em Biblioteconomia, Arquivologia e Museologia 
teriam nos programas de ciência da informação o seu espaço de formação pós-graduada e a devida preparação para a docência e a pesquisa.

\section{Um novo regime de informação? - algumas questões finais}

Como foi lembrado no início desse artigo, já há algumas décadas percebe-se um deslocamento do foco da questão do conhecimento e da informação das esferas estatais, públicas e educacionais para a esfera privada, econômica e mercadológica, a partir da globalização do mundo, das políticas neo-liberais e a conseqüente diminuição do Estado em relação a períodos anteriores. Nesse contexto, transforma-se o próprio entendimento do que seja ciência e atividade científica, tanto quanto dos ambientes institucionais de gestão, produção, transferência e uso das informações e dos conhecimentos, o que parece constituir uma fase de transição para um outro regime de informação.

$\mathrm{Na}$ literatura da Ciência da Informação, nos estudos de seus pesquisadores e estudantes, na prática profissional, nota-se um aumento substantivo e até avassalador da literatura e do discurso da "gestão do conhecimento e da informação" com foco modelar e aplicativo nas organizações, sobretudo empresariais. Entretanto, e apesar das exceções de costume, a área se defronta com uma abundante literatura e discursos concorrentes acerca da informação nas organizações, onde prevalece uma visão pragmática e operacional da informação.

A literatura assim gerada parece redundante e prenhe de modismos e, muitas vezes, se tem a impressão de que "as pessoas parecem gostar de ouvir aquilo que já sabem". E pergunta-se: como provocar uma ruptura nessa abordagem e modo de problematizar os aspectos gerenciais, políticos e sociais da informação e do conhecimento?

Existe, por outro lado, uma dificuldade inerente à cultura acadêmica, que é a de operar a transição da abordagem do conhecimento e da informação com foco no Estado e nas instituições acadêmicas e educacionais, para uma outra configuração de mundo, onde entram em cena outros atores, objetos, e novas relações de poder em torno do valor de mercado da educação, do conhecimento e da informação. As Ciências da Informação, afinal, tradicionalmente, como acentua Daniel Bougnoux, se ocupam da perenidade da informação, dos acervos, das memórias. Como realinhar seus pressupostos para um contexto mercadológico informatizado e em constante transformação, onde se matizam linguagens, discursos e narrativas concorrentes?

É necessário um ajuste de passo e compasso do tempo lento e depurado da pesquisa com a velocidade acelerada das novas mídias tecnológicas e as necessidades constantes de reconfiguração das práticas e processos organizacionais, para não falar de algo mais fundamental: os atores sociais que preenchem esses espaços. Mas sobretudo, é fundamental bem equacionar, nas pesquisas, como refletir sobre a convergência entre a sociedade de mercado e a racionalidade tecnológica que, segundo o teórico da comunicação Martin-Barbero (2003), dissocia a 
sociedade em sociedades paralelas: a dos conectados com a infinita oferta de bens e saberes e a dos excluídos, cada vez mais, tanto dos bens quanto da capacidade de decidir. Pergunta-se: como os estudos e as instituições de pesquisa e suas representações e associações, em diferentes contextos sociais e organizacionais, estão traduzindo esses desafios que o novo cenário mundializado apresenta? E em quem movimentos, conflitos e estratégias do campo de estudos da ciência da informação eles se projetam?

Essas e outras questões ganham relevância num momento em que a ciência da informação adquire uma posição de reflexividade e autocompreensão da sua história e do seu campo epistemológico, assumindo de forma mais explícita, por meio de suas perguntas, teorias e métodos de pesquisa, sua inserção no campo das ciências sociais e humanas. Por outro lado, e talvez de forma historicamente, profissionalmente e academicamente mais acentuada do que em outras disciplinas sociais, deve resguardar a sua proximidade com os suportes tecnológicos e os ambientes das práticas informacionais e suas aceleradas mudanças.

Afinal, a vitalidade de um campo de saber pode ser dimensionada pela qualidade e amplitude da sua produção de conhecimentos, seu desenvolvimento tecnológico e a interatividade entre a pesquisa, a educação e os ambientes da prática.

Esses seriam alguns dos grandes desafios, tanto políticos quanto acadêmicos, da pesquisa em ciência da informação no Brasil, no contexto da transição para um novo regime de informação.

\section{Referências}

ANCIB-Associação Nacional de Pesquisa e Pós-Graduação em Ciência da Informação. Sugestões para a Comissão responsável pela elaboração do Plano Nacional de Pós-Graduação, período 2005/2010. Belo Horizonte: ANCIB, 2004

ANCIB-Associação Nacional de Pesquisa e Pós-Graduação em Ciência da Informação.Comentários e sugestões da ANCIB e da Representação de área junto à CAPES sobre a "Nova Tabela das Áreas do Conhecimento versão preliminar proposta para discussão", elaborada pela Comissão Especial de Estudos CNPq, CAPES, FINEP. Belo Horizonte: ANCIB, 2005

BOURDIEU, Pierre. Science de la Science et réflexivité. Cours du Collège de France 2000-2001. Paris: Raisons d'Agir Éd., 2001c

BOURE, Robert. SIC: I'institutionalisation d'une discipline. In: OLIVESI, Stéphane. Sciences de l'information et de la communication : objets, savoirs, discipline. Grenoble : Presses Universitaires de Grenoble, 2006, p. 245-258

BRASIL. Ministério da Educação. Plano Nacional de Pós-Graduação - PNPG 2005-2010. Brasília: CAPES, 2005 
COUZINET, Viviane. Médiations hybrides: le documentaliste et le chercheur en Sciences de I'Information.Paris: ADBS Éd., 2000c

CURY, Carlos R. J.. A pós-graduação no Brasil e o IV PNPG. In: WORKSHOP EM CIÊNCIA DA INFORMAÇÃO: políticas e estratégias de pesquisa e ensino na pós-graduação. Anais. Niterói: ANCIB/UFF, 2004, p.38-57

FROHMANN, Bernd. Taking information policy beyond information science: applying the actor network theory. $23^{\text {rd }}$ Annual Conference: Canadian Association for Inf. Science, 1995

FROHMANN, Bernd. O caráter social, material e público da informação. In: FUJITA, M. S.L., MARTELETO, R.M., LARA, M.L.G. de. A dimensão epistemológica da Ciência da Informação e suas interfaces técnicas, políticas e institucionais nos processos de produção, acesso e disseminação da informação. São Paulo: Cultura Acadêmica Ed.; Marília: Fundepe Ed., 2008, p. 17-34

GIBBONS, M. et al. The new production of knowledge; the dynamics of science and research in contemporary societes. London: Sage Publications, 1994

GOMES, Wilson. Avaliação da pós-graduação em Ciência da Informação: alguns pontos para sua compreensão e discussão. In: WORKSHOP EM CIÊNCIA DA INFORMAÇÃO: políticas e estratégias de pesquisa e ensino na pós-graduação.Anais. Niterói: ANCIB/UFF, 2004, p. 67-80

GONZALEZ DE GÓMEZ, Maria Nélida. Novos cenários políticos para a informação. Ciência da Informação, v. 31, n.1, p. 27-40, 2002

ODDONE, Nanci. O IBBD e a informação científica: uma perspectiva histórica para a ciência da informação no Brasil. Brasília, Ciência da Informação, v.35, n.1, p. 45-56, jan./abr., 2006

RIBEIRO, Renato J. Terminou a avaliação trienal 2007 (1.0). In: CAPES. Artigos de avaliação trienal. Brasília: CAPES, 2007

Disponível em: http://www.capes.gov.br/servicos/sala-de-imprensa/57artigos/2401-artigos

Consultado em: agosto de 2009

SCHWARTZMAN, Simon. Modos de produção do conhecimento científico e tecnológico e as oportunidades para o setor de ensino particular. VI Encontro Nacional de Pós-Graduação nas IES Particulares. Anais. Salvador, 2005

SCHWARTZMAN, S.,BERTERO, C., KRIEGER, E.M., GALEMBECK, F. Science and Technology in Brazil: a new policy for a Global Word, vol. 1. Rio de Janeiro: Fundação Getúlio Vargas, 1995

WORKSHOP EM CIÊNCIA DA INFORMAÇÃO: Políticas e Estratégias de Pesquisa e Ensino na Pós-Graduação. Anais. Niterói: ANCIB-Associação 
Nacional de Pesquisa e Pós-Graduação em Ciência da Informação, 2004, $192 \mathrm{p}$. 